\title{
The pattern of intraday liquidity in emerging markets: The case of the Amman Stock Exchange
}

\author{
Muna Flaih Alabed, and Ritab Al-Khouri* \\ *Department of Economics and Finance, College of Business and Economics, PO Box \\ 2713, Doha, Qatar. \\ Tel: + 974 5400929, Fax: + 974 4851564, E-mail: r.al-khouri@qu.edu.qa
}

Received (in revised form): 5th July, 2008

Muna Alabed finished her MBA from Yarmouk University in 2005 and worked at the Amman Financial Authority for one year. Currently, she is working on her PhD in Economics at the University of Texas, USA. Her research interest is capital markets and portfolio management.

Ritab Al-Khouri is a full professor of Finance at Yarmouk University in Jordan. She is currently on leave, teaching at Qatar University. She graduated from the University of Wisconsin at Madison in the USA, and has published many articles in different national and international journals. Her research interests include portfolio management, corporate finance, corporate governance and international finance.

\section{Practical application}

The study of intraday liquidity dynamics for stocks listed in Amman Stock Exchange (ASE) is important to different parties including policy makers, investors, academics, as well as, other participants in the ASE. Characterising the behaviour of trading and liquidity components can help traders, national and foreign, in this market build their trading strategies and take their positions accordingly. Using different liquidity measures can help exchange officials and regulators better interpret and monitor the market fluctuations based on these different measures.

Journal of Derivatives \& Hedge Funds, Vol. 14 Nos. 3/4, 2008, pp. 265-284 (C) 2008 Palgrave Macmillan 1753-9641

\begin{abstract}
This study provides an empirical analysis of several intraday liquidity dynamics for stocks listed on the Amman Stock Exchange (ASE) using transaction data for the period from 1st January, 2005 to 31st August, 2005. We used a cross-market index, which is composed of 37 stocks, to estimate different liquidity proxies. These liquidity proxies are represented graphically to check for intraday commonalities. The analysis demonstrates that volume measures, bid-ask spread, instant trades, and number of large trades exhibit a U-shape, liquidity ratio has a smooth L-shape, while waiting-time-to-trade exhibits an
\end{abstract}

inverse U-shape. The same results are observed for the case of an individual stock. The results reveal that the ASE's highest activity levels are at market open and close, whereas it is least active between 11.20 and $11.35 \mathrm{am}$, suggesting a possible high information asymmetry level at open and intensive large traders' activities at close.

Journal of Derivatives \& Hedge Funds (2008) 14, 265-284. doi:10.1057/jdhf.2008.18

Keywords: intraday liquidity; transaction data; market concentration; Amman Stock Exchange 


\section{INTRODUCTION}

This study uses minute-by-minute transaction data on 37 companies listed on the Amman Stock Exchange (ASE) over the period 1st January, 2005 to 31st August, 2005 (165 trading days) to test the statistical patterns between different cross-market liquidity proxies. Liquidity is measured via transactions, that is ex post, after periodically regrouping transaction data through several measures representing the four liquidity dimensions identified by Kyle ${ }^{1}$ and Harris ${ }^{2}$ : immediacy, tightness, depth, and resiliency. The same analysis is carried out considering the case of an individual stock with further investigation of market concentration.

More specifically, our study aims to answer the following questions:

(1) How do different market-wide intraday liquidity measures behave during the day?

(2) How are the different liquidity measures related to each other?

(3) Does an intraday pattern for market concentration exist?

The ASE is considered to be one of the most important exchanges in the Middle East, and it has taken various measures to improve its microstructure, considering international standard and the experiences of other major stock exchanges. First, the ASE recently underwent a structural break that likely affected liquidity, namely equity market liberalisation. These liberalisations give foreign investors the opportunity to invest in domestic equity securities up to 100 per cent in some sectors. Secondly, like many emerging markets, the ASE has automated its trading system in order to attract order flows, increase liquidity through improved market transparency, and enhance quality of execution. On 26th March, 2000, the Jordanian stock market computerised its trading system and eliminated the traditional trading floor on which brokers exchanged securities. Thirdly, the market has witnessed an increase in the number of listed companies throughout the years, which gives an indication of the economic growth in Jordan. Market capitalisation has also increased since the establishment of the ASE market. At the end of 2004, 192 companies were listed on the market, with a total market capitalisation of Jordanian dinars (JDs) 13,033.8m. Even with all this development, the ASE, like any emerging exchange, is still characterised by low turnover (TO) ratio, low liquidity, low transparency, and high volatility as compared to the developed markets.

Frictions in the ASE such as the existence of trading and transaction costs, short sales restrictions, the existence of price limit, and illiquidity are expected to impact price formation. The two main restrictions of 5 per cent daily price limits imposed on stock prices, along with the restriction on short selling used to dampen volatility that affects small investors, might have major implications for stock prices. The impact of these restrictions on liquidity, volatility, and consequently return has recently attracted attention from policy makers, investors, and academics in the emerging stock market of Jordan.

The contribution of this paper is twofold: first, we look at the effect of different institutional characteristics on liquidity and the behaviour of investors in a small market, the ASE. Characterising the behaviour of trading and liquidity components can help traders in this market, both national and foreign, build their trading strategies and take their positions accordingly. Secondly, we use different 
liquidity measures. These can help exchange officials and regulators to better interpret and monitor the market fluctuations based on these different measures.

This paper is organised as follows. The next section presents the literature review. The subsequent section outlines the institutional characteristics of the ASE. Further section describes our data and methodology and presents our Analysis. The last section summarises and concludes.

\section{LITERATURE REVIEW}

Madhavan, ${ }^{3,4}$ Stoll, ${ }^{5}$ and Freyre-Sanders et al. ${ }^{6}$ survey the literature on the market microstructure; their papers provide useful comprehensive reviews of theoretical, empirical studies. The behaviour of prices depends on the trading mechanisms' ability to match the buying and selling desires of market participants, which involves the provision of liquidity. ${ }^{7}$

One strand of literature related to the theoretical and empirical work aims to determine the trading costs and the process by which information is ultimately translated into realised prices and volumes (ie spread formation). Prominent studies in this group focus on the role of a liquidity provider; the most common factors identified to cause price movements are order processing, inventory control, and adverse selection.

The early work of Demsetz ${ }^{8}$ and Tinic ${ }^{9}$ shows that a liquidity provider incurs order processing costs, as well as additional risk, by providing intermediation and immediacy services to the rest of the market participants, and hence should be compensated for by the bid-ask spread. The role of liquidity providers reduces the risk of not executing the trade and this imposes an additional (order processing) cost friction, which is therefore expected to be higher for illiquid, thinly traded securities. The study finds that trading activity measures have a significant negative impact on spread. Demsetz's ${ }^{8}$ results motivated further research regarding spread measures and determinants of trading costs.

A second factor contributing to bid-ask spread is inventory control costs. ${ }^{10-13}$ In these papers, the liquidity provider has an optimal inventory position that he prefers to hold based on the degree of his risk aversion; trades force him away from his initial position, therefore he changes spread to restore the initial position. Spread becomes wider (narrower) when a liquidity provider is away from (below) his position.

Recent work suggests models of the impact of information on market prices. Copeland and Galai, ${ }^{14}$ Glosten and Milgrom, ${ }^{15}$ Kyle, ${ }^{1}$ Glosten, ${ }^{16}$ Easly and O'Hara, ${ }^{17}$ and Admati and Pfleiderer ${ }^{18}$ suggest that bid-ask spread exists even if both order processing and inventory costs have a 0 value due to information-based trading.

A liquidity provider deals with both informed and uninformed traders. An informed trader possesses private information that allows him to better estimate an asset's true value, and therefore makes profits at the expense of the liquidity provider. An uninformed trader does not possess private information but transacts for different reasons not necessarily related to fundamentals. Informed traders will buy (sell) only if the price is below (above) what they assume to be true value, otherwise they stop trading. A liquidity provider will lose to this type of trader, but his losses are offset by gains from uninformed traders, and since a market-maker cannot necessarily distinguish between informed and uninformed traders, he will charge the spread to everyone in order to break even. 
Although a liquidity provider cannot determine with certainty the true value of the security, he can learn from the sequence of trades. ${ }^{15,16,19}$ Sequential buy (sell) orders make him revise his beliefs for the probability that the true value is higher (lower) and that they therefore widen (narrow) the spread. No trade provides information as well, according to Easly and O'Hara, ${ }^{17}$ it is perceived as though no new private information exists and therefore it is unlikely to trade against an informed trader. Therefore, an adverse selection cost is imposed as a result of information asymmetry. Hasbrouck ${ }^{20}$ notes that the asymmetric information price impact is positive and has a concave function of the trade size (TS), and that information asymmetries are more significant for smaller firms.

To protect themselves from imposed adverse selection costs, informed traders might strategically hide behind the activity of uninformed traders by either spreading their trades or by distributing them over time before information becomes common knowledge, ${ }^{1}$ or by trading when volume is high. ${ }^{18}$. This strategic tendency of market participants results in an intraday pattern of trading volumes, where higher trading volumes at certain periods are associated with higher adverse selection costs as probability of existing informed traders increase. Uninformed traders can reduce their adverse selection costs by trading in a basket of securities (ie stock indices) rather than in an individual stock (it is unlikely for market-wide information to exist). The impact of information asymmetry is minimised as the number of stocks in the basket increases. $^{21}$

Stoll ${ }^{22}$ tested the hypothesis of combined effect and the results show that order processing, inventory control, and adverse selection costs are constant in percentage and are equal to 47,10 , and 43 per cent, respectively.

Lin et al. ${ }^{23}$ show that trading volume, relative spreads, and information costs decrease over the day for all TS categories but the largest 1 percentage. The order processing cost tends to be highest during the middle of the day, while the persistence of trade arrivals is highest at the end of the day.

Theory suggests that at the beginning of the trading day, information asymmetry, and hence adverse selection cost, is high (accordingly volatility and bid-ask spreads are also high). Owing to learning from trading activities and price discovery, information asymmetry decreases (adverse selection cost decrease), but at the end of the trading day, the risk of carrying inventory overnight for a market-maker increases, causing spreads to widen again (inventory control cost increase). Cushing and Madhavan ${ }^{24}$ provide empirical evidence that higher trading costs toward market close are due to increased institutional trading activities at closing. This behaviour results in a U-shape of trading volume, volatility, and average bid-ask spread over the trading day.

Literature on emerging markets using microstructure data is still rare. Emerging markets are classified as being volatile, but with significant returns that in turn should be balanced with liquidity concerns of those markets. Ghysels and Cherkaoui ${ }^{25}$ examine models of effective spreads, as well as the price impact of large block trades in emerging markets, to test whether trading costs have significantly changed since the stock market microstructure reforms. They conclude that none of the models used were adequate or appropriate for the conditions of emerging markets. Despite the shortcomings of the models 
tested, they show that spreads tended to increase rather than decrease. The increase in spreads, however, is not purely a reflection of increased overall volatility in the market. The price impact of large block trades, when present, also increased.

\section{INSTITUTIONAL CHARACTERISTICS OF THE ASE}

\section{Establishment of the ASE}

The Amman Financial Market (AFM) started operating as both a regulator and a stock exchange on 1st January, 1978; before this date, trading used to take place via a number of brokerage firms on the unregulated market, until the temporary law No. 31 for the year 1976 was set. The Securities Law for the year 1997 was promulgated in the mid-1990s, whereby the Jordan Securities Commission was set up to assume legislation, supervision, and monitoring in succession to the AFM. The $\mathrm{ASE}^{26}$ was established in March 1999 as an administratively and financially independent non-profit institution managed by the private sector.

A year following its establishment, the ASE initiated a modernisation, upgrading and automation programme for its trading environment. The ASE made a successful transition from the manual system to an electronic trading system. The ASE operates the French Electronic Trading System NSC-Unix hardware.

\section{The trading process in ASE}

The trading day for stock exchange markets consists of four main phases: pre-opening, opening, continuous trading, and closing. At the pre-opening phase (9.30-10.00am), orders are submitted by the brokers to the system, and are then automatically recorded and ranked according to priorities on the central order book, but not executed. Orders are ranked first according to price priorities (descending for buy orders and ascending for sell orders), then by time priorities (first in, first out), and then by size (if orders with the same price are entered simultaneously, larger orders are given priority). At this stage, a broker has the right to cancel or modify his orders that were entered beforehand. An indicative equilibrium price $(I E P)$ is calculated and immediately disseminated each time a new order is entered or modified. For each security at the opening phase (10.00am), the system matches the orders present on the order book and determines a price - the last calculated IEP immediately before the opening - as the opening price. Mutually compatible orders are executed immediately if the estimated IEP is inside the authorised variation brackets. In this way, the pre-opening phase is an auctioning phase where the opening price is the market clearing price for the moment of market open.

During the continuous pricing session (10.00-12.00am), orders submitted to the book are executed if there are corresponding orders on the opposite side of the order book, and kept on the book if not matched off immediately. Pricing happens continuously corresponding to executed orders and moves up and down within the authorised limits. The last traded price is the closing price upon which the brackets for the next day are determined (reference price). This price is reviewed by the ASE surveillance department's staff, who intervene to determine this reference price if a trading violation (known as marking the close) is detected.

Orders entered to the system can stipulate either limited (pre-stated) or market price, which means at the best price available. At the pre-opening phase, a broker can enter orders 
with open price, which is equivalent to market price order at the continuous trading session and should be executed at estimated IEP. Open-price orders take price priority on the order book and if the quantity placed in an open order is not fully executed at opening, the remaining part automatically becomes a market order with normal priority.

According to the validity on the book, orders are either valid for a day, a limited date, good till cancelled. The ASE also allows hidden orders: a broker has the right to define a minimum quantity visible in the order book and hide the remaining quantity. This option helps to minimise the price impact cost of large trades.

All stocks listed on the ASE are traded and priced in a continuous fashion. A stock, however, may appear occasionally in a status other than traded. A stock is suspended when there is going to be a corporate action or a financial operation affecting the value of a firm's stock or upon request from relevant authorities, and is frozen if any entered order is automatically stopped by the electronic trading system because it provokes trades at price outside the authorised variation margin. The stock is reserved at the trading start if the IEP was estimated below or above the authorised limits or when there is an open price order at one side of the book and there are no trades at the opposite side.

\section{DATA AND METHODOLOGY}

\section{Sample selection and data filtering}

\section{Sample selection}

This study uses minute-by-minute transaction data on 37 companies listed in ASE over the period 1st January, 2005 to 31st August, 2005 (165 trading days). The data are collected by the researchers from the intraday files provided by the exchange. Data used for empirical analysis in this study are price, quantity, volume in JDs for each executed transaction, and the time when this transaction took place to the nearest second for each trading day for each individual stock independently. Stocks selected to be included in the sample are those that have satisfied the following conditions:

(1) Are listed on the ASE before 1st January, 2005 and have not been de-listed before 31st August, 2005 or suspended for any legislatorial reason other than the days for general assembly meetings. This condition excludes the days when no transaction took place only because no orders are available on one or both sides of the book.

(2) Are traded during at least 90 per cent of actual trading days.

(3) Have at least 50 contracts a day on average.

(4) Did not have influential corporate actions such as mergers or stock splits during the study period.

Thirty-seven stocks are qualified accordingly and are listed along with their statistics in Table A1 in Appendix A.

\section{Data filtering}

For each day and for each individual stock (1) transactions executed at the same point in time and the same price are aggregated into one trade, (2) transactions executed at first minute after openings are eliminated, and (3) the two-hour trading sessions (10.00-12.00am) are divided into 24 five-minute intervals.

Instant trades that are executed at the same price are assumed to have been originally initiated as one trade (probably one order at one 
side of the book being executed against more than one order on the opposite side of the book), and for this reason they are regrouped into one trade. Opening transactions (the first minutes' transactions) are eliminated because at market open, the ASE operates as a call market, where orders are accumulated during the 30-minute pre-opening phase, and then becomes a continuous market right after the market open.

\section{Methodology}

\section{Measuring intraday market liquidity}

In order to characterise the behaviour of intraday market liquidity on a cross-sectional level, and on an individual security level, several measures of market liquidity are employed, representing the different liquidity dimensions.

The first liquidity indicator used here is market depth. Admati and Pfleiderer ${ }^{18}$ provide one of the first studies that investigate volume intraday patterns as being a standard liquidity measure. Trading volume, however, could be measured with different dimensions. The most popular measures are TS, which measures trading volume via the number of shares exchanged, TO, which measures trading volume via the monetary value of those shares, and number of trades (NT), which measures trading volume via the number of transactions by which those shares were exchanged. Those measures are, however, closely interrelated to each other. Total volume in a particular period is the sum of the sizes of individual trades.

These three trading volume measures (TS, TO, and NT) are used in the current study and are measured as follows:

$$
T S_{t}=\sum_{i=1}^{N T_{t}} T S_{i}
$$

$$
\begin{gathered}
T O_{t}=\sum_{i=1}^{N T_{t}} P_{i} T S_{i} \\
N T=\sum_{i=1}^{n} t_{i}
\end{gathered}
$$

where $N T_{t}$ is the number of trades between time $t-1$ and $t, T S_{i}$ is the number of shares in trade $i$, $P_{i}$ is the price of trade $i$, and $t_{i}$ refers to the particular transaction $i$.

Although volume measures are the most common liquidity proxy used in stock exchanges and in literature describing interday and intradaily patterns, it fails to sufficiently reflect the market impact of price movements and variant sizes of different trades because it considers small and large size trades as having the same effect. ${ }^{27}$ Other studies claim that information contained in trading frequency is higher than in TS or $N T .^{28}$ Therefore, other liquidity proxies are employed in order to capture the different liquidity dimensions.

The immediacy dimension is measured by the number of instant trades (NI), that is trades taking place subsequently within a very short time (ie within seconds):

$$
N I=\text { Number of } D_{i t} \text { such that } D_{i t} \leq \text { seconds }
$$

where $D_{i t}$ is the time duration in seconds between transactions $i+1$ and $i$. Ekinci ${ }^{28}$ defines instant trades to be those occurring subsequently within two seconds. In the current study, however, time duration considered in order to estimate this measure is ten seconds because stocks listed on the ASE are generally described as thinly traded.

Waiting-time-to-trade (WT) is another common time-related liquidity proxy, as it measures the time it takes to exchange a stock for money and can be seen as an intensity proxy for market 
activity. This study examines the waiting time between subsequent trades. The mean of $W T$ is used to express the value of this liquidity proxy when considering a certain time period

$$
W T=\frac{1}{n} \sum_{i=1}^{n}\left(T r_{i}-T r_{i-1}\right)
$$

Market tightness refers to the cost of immediacy, and is widely measured by the different bid-ask spread estimators. One common limitation facing the estimation of market tightness is the unavailability of data regarding quoted prices. To overcome this shortfall, we will define estimators for bid-ask spread that depend on data of transacted orders (ie executed prices), which are usually available. In this study, the popular Roll ${ }^{29}$ Spread estimator is employed in order to establish a proxy for implied trading costs, despite the critiques of many researches providing evidence that Roll's spread explains only order processing cost and fails to contain other costs such as the marketmaker's inventory control cost and information asymmetry cost, and hence that the measured spread is underestimated. Faced with the same limitation in the ASE, spread is measured by the Roll estimator. The underestimation of the measure, however, is expected to be less influential in the case of stocks listed on the ASE, because there are no market-makers, and hence inventory control costs do not exist. The Roll Spread $(R S)$ is

$$
R S=2 \sqrt{-\operatorname{cov}\left(\Delta P_{t}, \Delta P_{t-1}\right)}
$$

where $\Delta p_{t}, \Delta p_{t-1}$ are price changes at time $t$, $t-1$, respectively, and $S$ is one-half bid-ask spread.

Another measure that proxies for liquidity is the number of big trades $(B T)$ within a defined time period. Easly and O'Hara ${ }^{19}$ argue that big trades signal the identity of the trader such that institutional traders usually initiate large trades. Therefore, the TS that exceeds 3,000 shares is considered a big one.

$$
B T=N T_{t} \text { such that } T S \geq 3000 \text { shares }
$$

The final liquidity proxy used is the liquidity ratio $(L R)$, which is related to resiliency dimension. The liquidity ratio employed in this study is $L R(3)$, which relates the sum of absolute returns to the NT and therefore measures the average price change of a trade. Accordingly, a high average price change of a trade indicates low liquidity.

$$
L R_{t}=\frac{\sum_{i=1}^{N T_{t}}\left|R_{t i}\right|}{N T_{t}}
$$

where $R_{t, i}=\left(P_{i}-P_{i-1}\right) / P_{i-1}$.

For each independent stock, liquidity measures are estimated on a daily basis for each interval, resulting in 24 observations representing the five-minute intervals previously described for each company separately. The number of daily observations can sometimes be less than 24 when there is one or more tradeless interval on a particular day. The interdaily estimated measures are then aggregated or averaged, resulting in 24 observations for each company and representing the whole period under study. Trading-volume-per-interval measures (ie TS, NT, and TO) are aggregated for each day. A value of 0 is assigned to the tradeless intervals, which is in fact the actual volume when no trade takes place. The same method is used when estimating $I T$ and $B T$. When estimating the averages for $R S, L R$, and $W T$, however, this method cannot be employed because the nonexistence of executed trades does not mean that spread has a 0 value. Moreover, 
assigning a value of 0 to the liquidity ratio can substantially affect the estimated average for the period. Accordingly, average $R S, L R$, and $W T$ are estimated using only trading days and excluding the days where no trades existed for each interval, as suggested by Chordia et al. ${ }^{30}$

Therefore, our analysis will focus on intraday cross-sectional index of the different aforementioned liquidity measures. This index is represented by the averages of the crosscompanies' measures. And the values assigned for different liquidity measures are plotted to visually characterise the intraday behaviour of each measure separately.

Using the 37 stocks' estimated averages of the 24 interval observations, the correlations between our different liquidity measures are calculated. Moreover, the 37 stocks are classified according to their liquidity. After defining the most liquid stock, the preceding procedures used to graphically represent the liquidity measures are repeated, this time considering an individual stock for comparison purposes. The values used to estimate the 24 interval averages are the daily five-minute intervals' estimated values of each liquidity proxy.

\section{Analysis}

\section{Descriptive statistics}

In order to measure intraday liquidity on the ASE and to characterise the behaviour of the different established measures, the transaction data for 37 stocks are used. The sectoral presentation is not taken into consideration. Nevertheless, it is worthwhile to mention that the sample does not include insurance companies because this sector of the ASE consists generally of small-cap companies that are thinly traded and the daily traded volume on this sector accounts for not more than 1 per cent, on average, of the daily total market volume. The sample stocks consist of 11 banks, 18 service companies, and 8 industrial companies.

The total number of transactions for the sample is 1,001,944 before filtering, and 576,168 after filtering. The filtering procedures decreased the number of transactions by quite a large percentage (42.5 per cent). This highlights the significance of the opening trades, which is a preliminary indication that liquidity is significantly high at the opening, and/or that the number of re-grouped trades is high, meaning that a significant number of initiated orders are each matched with a number of smaller trades on the opposite side of the book, which is a preliminary indication of illiquidity.

Each of the measures RS, NT, TO, TS, BT, IT, $L R$, and $W T$ in equations (1)-(8) shows a positive excess kurtosis. Moreover, all measures, except of $W T$, are skewed to the right, indicating that none of the estimated measures are normally distributed. Table 1 lists the observations measured for each stock that are averaged to estimate the 24 cross-market index' values of each liquidity measure, while Table 2 lists the statistics of the measured proxies of liquidity for the index composed of the 37 stocks.

\section{Intraday liquidity patterns}

Table 3 exhibits the Pearson correlations between the eight different liquidity measures estimated for the cross-market index composed of the 37 stocks. As expected, WT is negatively correlated with all other measures. Bid-ask spread $R S$ is highly correlated with the number of $B T$, which signals the price impact of large trades. The price impact of large trades can also 
Table 1: Observations of cross-sectional liquidity proxies estimated for intraday liquidity pattern investigation

\begin{tabular}{|c|c|c|c|c|c|c|c|c|c|c|c|}
\hline Interval & $R S$ & $N T$ & $R N T$ & TO & RTO & TS & RTS & $B T$ & $I T$ & $L R$ & $W T$ \\
\hline 1 & 0.043 & 535.5 & 3.50 & 7,196,987 & 4.97 & $1,272,800$ & 4.62 & 206.4 & 178.6 & 0.667 & 0:02:05 \\
\hline 2 & 0.025 & 701.7 & 4.59 & $8,119,851$ & 5.62 & $1,429,908$ & 5.26 & 166.1 & 282.7 & 0.288 & $0: 02: 55$ \\
\hline 3 & 0.024 & 697.7 & 4.57 & $7,607,982$ & 5.30 & $1,376,854$ & 5.07 & 155.6 & 273.5 & 0.262 & $0: 02: 21$ \\
\hline 4 & 0.021 & 686.4 & 4.49 & $7,218,443$ & 5.00 & $1,276,491$ & 4.69 & 148.4 & 255.5 & 0.248 & $0: 02: 29$ \\
\hline 5 & 0.022 & 680.5 & 4.45 & $7,220,223$ & 5.03 & $1,285,098$ & 4.73 & 142.8 & 245.1 & 0.224 & $0: 02: 20$ \\
\hline 6 & 0.017 & 676.0 & 4.42 & $6,681,327$ & 4.60 & $1,211,202$ & 4.47 & 134.8 & 238.8 & 0.215 & $0: 02: 22$ \\
\hline 7 & 0.018 & 658.6 & 4.31 & $6,068,862$ & 4.21 & $1,146,770$ & 4.21 & 130.9 & 225.4 & 0.210 & $0: 02: 27$ \\
\hline 8 & 0.013 & 644.0 & 4.22 & $6,063,363$ & 4.20 & $1,090,247$ & 3.97 & 121.9 & 214.6 & 0.197 & $0: 02: 28$ \\
\hline 9 & 0.014 & 635.8 & 4.16 & $6,009,238$ & 4.13 & $1,127,145$ & 4.08 & 124.7 & 211.0 & 0.190 & $0: 02: 22$ \\
\hline 10 & 0.014 & 624.3 & 4.09 & $5,734,010$ & 3.98 & $1,054,973$ & 3.87 & 115.8 & 204.0 & 0.189 & $0: 02: 30$ \\
\hline 11 & 0.012 & 615.7 & 4.03 & $5,571,656$ & 3.85 & $1,063,061$ & 3.90 & 114.9 & 208.6 & & $0: 02: 43$ \\
\hline 12 & 0.013 & 620.5 & 4.06 & $5,487,485$ & 3.79 & $1,067,901$ & 3.91 & 113.0 & 211.0 & 0.180 & $0: 02: 30$ \\
\hline 13 & 0.016 & 608.1 & 3.98 & $5,466,103$ & 3.78 & $1,029,788$ & 3.78 & 111.3 & 198.1 & 0.179 & $0: 02: 36$ \\
\hline 14 & 0.012 & 593.4 & 3.88 & $5,482,578$ & 3.77 & $1,051,134$ & 3.83 & 108.9 & 190.5 & 0.175 & $0: 02: 39$ \\
\hline 15 & 0.013 & 586.2 & 3.84 & $4,972,572$ & 3.45 & $1,003,952$ & 3.69 & 109.8 & 188.6 & 0.174 & $0: 02: 44$ \\
\hline 16 & 0.012 & 578.9 & 3.79 & $4,991,715$ & 3.45 & $1,000,128$ & 3.62 & 10 & 178.7 & 71 & $0: 02: 28$ \\
\hline 17 & 0.01 & 581.9 & 3.81 & $5,210,183$ & 3.57 & $1,029,528$ & 3.69 & 107.6 & 179.4 & 0.166 & $0: 02: 36$ \\
\hline 18 & 0.012 & 573.8 & 3.76 & $5,213,667$ & 3.62 & $1,043,020$ & 3.79 & 108.8 & 169.9 & 0.168 & $0: 02: 39$ \\
\hline 19 & 0.012 & 563.3 & 3.69 & $4,812,364$ & 3.29 & 977,614 & 3.55 & 104.4 & 164.1 & 0.172 & $0: 02: 59$ \\
\hline 20 & 0.013 & 588.9 & 3.85 & 4,939,506 & 3.40 & $1,000,384$ & 3.63 & 3.1 & 174.4 & 68 & $0: 02: 39$ \\
\hline 21 & 0.013 & 600.8 & 3.93 & $5,314,571$ & 3.65 & $1,046,048$ & 3.78 & 110.8 & 179.6 & 0.175 & $0: 02: 42$ \\
\hline 22 & 0.012 & 638.3 & 4.18 & $5,582,808$ & 3.87 & $1,098,565$ & 4.02 & 117.3 & 191.6 & 0.179 & $0: 02: 36$ \\
\hline 23 & 0.016 & 703.3 & 4.60 & $6,131,203$ & 4.22 & $1,228,407$ & 4.44 & 127.3 & 220.2 & 0.188 & $0: 02: 25$ \\
\hline 24 & 0.02 & 883.9 & 5.79 & $7,625,558$ & 5.27 & 1,499,291 & 5.40 & 158.1 & 315.2 & 0.225 & $0: 01: 51$ \\
\hline
\end{tabular}

be inferred from the high correlation between $R S$ and $L R$, and between $B T$ trades and $L R$, since liquidity ratio relates the average price change to the NT. This is why $L R$ is negatively related to NT. Actually, volume measures (TS, $T O$, and $N T$ ) are interlinked, and it is expected that they exhibit high correlation with each other. The same is true when considering the correlation between $N T$ and the number of instant trades $I T$.
It is obvious from Figures 1-5, which plot the 24 intraday intervals' estimates of each liquidity proxy for the composed index, that RS, NT, TO, TS, BT, and IT exhibit the popular U-shape observed by many researchers' work in this field, while $L R$ can be better described as a smooth $\mathrm{L}$-shape, and $W T$ as an inverse U-shape.

Figures 1-5 illustrate the behaviour of the estimated cross-market's averages of the 24 intervals. 
Table 2: Descriptive statistics for different cross-market liquidity measures

\begin{tabular}{|c|c|c|c|c|c|c|c|c|c|c|c|}
\hline & $R S$ & NT & $R N T$ & TO & RTO & $T S$ & RTS & $B T$ & $I T$ & $L R$ & $W T$ \\
\hline Mean & 0.017 & 636.563 & 4.166 & $6,030,094$ & 4.168 & $1,142,096$ & 4.167 & 127.213 & 212.463 & 0.216 & 0.002 \\
\hline Median & 0.0135 & 622.4 & 4.075 & $5,658,409$ & 3.925 & $1,079,074$ & 3.94 & 116.55 & 206.3 & 0.184 & 0.0017 \\
\hline Maximum & 0.043 & 883.9 & 5.79 & $8,119,851$ & 5.62 & $1,499,291$ & 5.4 & 206.4 & 315.2 & 0.667 & 0.0021 \\
\hline Minimum & 0.01 & 535.5 & 3.5 & $4,812,364$ & 3.29 & $977,614.4$ & 3.55 & 104.4 & 164.1 & 0.166 & 0.0013 \\
\hline s.d. & 0.007 & 70.883 & 0.464 & $981,562.8$ & 0.688 & $146,925.2$ & 0.542 & 24.820 & 38.954 & 0.101 & 0.000 \\
\hline Skewness & 2.404 & 1.719 & 1.729 & 0.693 & 0.690 & 0.992 & 0.928 & 1.601 & 1.024 & 3.892 & -0.606 \\
\hline Kurtosis & 9.425 & 7.176 & 7.232 & 2.216 & 2.214 & 2.912 & 2.704 & 5.351 & 3.376 & 17.823 & 4.187 \\
\hline Sum & 0.397 & $15,277.5$ & 100 & $1.45 \mathrm{E}+08$ & 100 & $27,410,307$ & 100 & $3,053.1$ & $5,099.1$ & 5.19 & 0.04196 \\
\hline Sum. Sq. Dev. & 0.001 & $115,561.5$ & 4.96 & $2.22 \mathrm{E}+13$ & 10.871 & $4.97 \mathrm{E}+11$ & 6.766 & $14,168.746$ & $34,899.8$ & 0.236 & 0.000 \\
\hline
\end{tabular}


Table 3: Pearson correlation between the cross-sectional liquidity proxies

\begin{tabular}{lllllllll}
\hline & $R S$ & $N T$ & \multicolumn{1}{l}{ TS } & \multicolumn{1}{l}{ TO } & \multicolumn{1}{c}{ LR } & \multicolumn{1}{c}{ BT } & \multicolumn{1}{l}{ IT } & \multicolumn{1}{l}{$W T$} \\
\hline$R S$ & 1 & 0.152 & 0.670 & 0.737 & 0.941 & 0.956 & 0.360 & -0.488 \\
$N T$ & 0.152 & 1 & 0.794 & 0.682 & -0.086 & 0.380 & 0.917 & -0.528 \\
$T S$ & 0.670 & 0.794 & 1 & 0.965 & 0.455 & 0.830 & 0.896 & -0.561 \\
TO & 0.737 & 0.682 & 0.965 & 1 & 0.533 & 0.873 & 0.860 & -0.511 \\
$L R$ & 0.941 & -0.086 & 0.455 & 0.533 & 1 & 0.868 & 0.099 & -0.432 \\
$B T$ & 0.956 & 0.380 & 0.830 & 0.873 & 0.868 & 1 & 0.565 & -0.563 \\
$I T$ & 0.360 & 0.917 & 0.896 & 0.860 & 0.099 & 0.565 & 1 & -0.464 \\
$W T$ & -0.488 & -0.528 & -0.561 & -0.511 & -0.432 & -0.563 & -0.464 & 1 \\
\hline
\end{tabular}

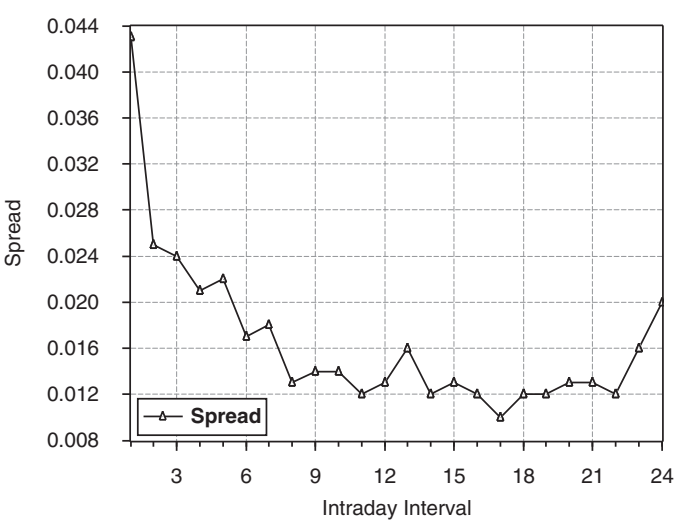

Figure 1: The average bid-ask spread

In Figure 2, the relative number of trades $(R N T)$, relative turnover $(R T O)$, and relative trade size (RTS) are used, rather than NT, TO, and $T S$, respectively, in order to standardise the scaling and combine their presentation into one graph. The relative value for this purpose is estimated as

$$
R X_{i}=\frac{X_{i}}{\sum_{i=1}^{24} X_{i}}
$$

where $X_{i}$ is the NT, TO, or TS for interval $i=1,2, \ldots, 24$.

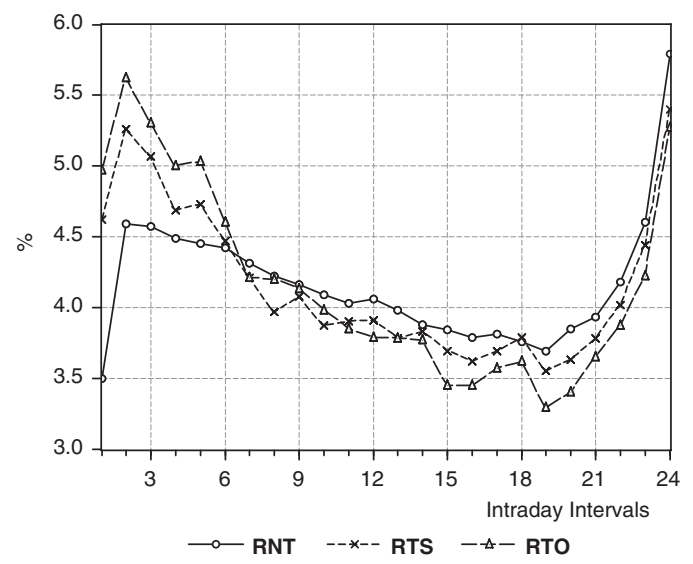

Figure 2: The relative average number of trades, relative average trade size, and relative average turnover

Figures $1-5$ reveal the strong liquidity level at the beginning and at the end of the trading day. The following is observed:

(1) Bid-ask spread in Figure 1 starts the trading day (10.00am) with its highest level (0.043) with an accelerated fall toward the second interval (10.5-10.10) and then continues to fall gradually throughout the trading day. Bid-ask spread reaches its minimum level of 0.01 at the 17 th interval (11.20-11.25) 


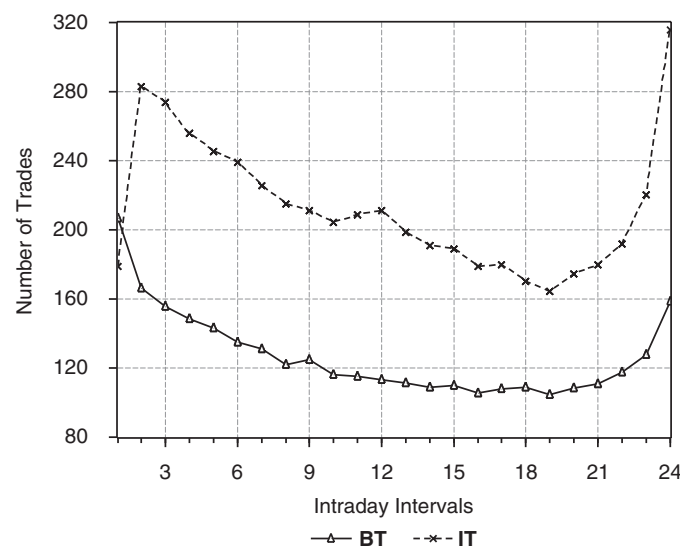

Figure 3: Number of big trades and number of instant trades

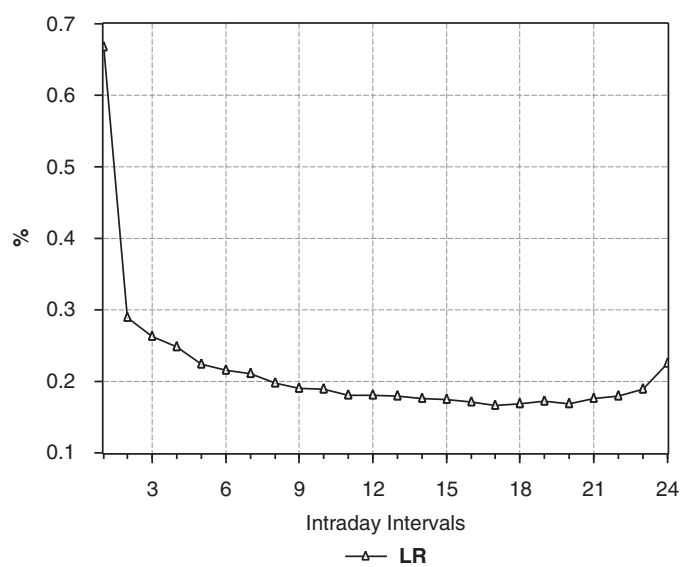

Figure 4: Liquidity ratio

and rises again toward the end of the trading session (11.45-12.00).

(2) In Figure 2, trading volume measures (RNT, RTS, and RTO) start with a substantial increase toward the 2nd interval (10.5-10.10), and decrease right after that throughout the trading session, until TO and $T S$ reach their minimum level at the 19th interval (11.30-11.35), and then all the measures increase substantially right after that.

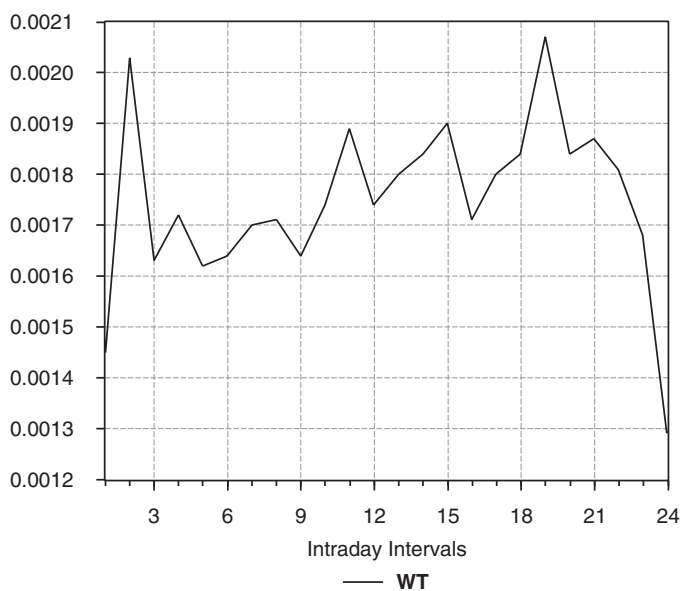

Figure 5: Waiting time between subsequent trades

(3) Number of BT and number of IT, as in Figure 4, exhibit the same pattern as NT, TO, and TS in Figure 2. Both are at their highest levels at the market open and toward the market close, and reach their minimum level at the 19th interval (11.30-11.35).

(4) In Figure 4, $L R$ falls sharply from its highest level at the open toward the 2nd interval and then continues to fall gradually in a smooth movement toward its lowest level at the 17th interval, followed by a small rise toward the end of the trading session.

(5) A common pattern is less obvious in the case of the $W T$ in Figure 5. It starts with a substantial increase followed with a substantial decrease throughout the first 10 min of the session, and then moves up and down with variant degrees and reaches its highest level at the 19th interval. It decreases substantially thereafter, until it reaches its lowest level at the market close. In its behaviour, $W T$ can be described as an irregular inverse U-shape. 
According to the observed behaviour of the eight liquidity measures employed, the highest liquidity levels at the ASE are at the market open and market close, whereas the lowest active trading period is between 11.20 and $11.35 \mathrm{am}$.

Obviously, there is a significant effect on the results caused by the filtering procedures when eliminating the first minute's trades. This action substantially decreased NT, TO, TS, and IT of the first interval. Eliminating these trades interprets the highest level of $L R$ at the market open as well, since it decreases the denominator of the ratio. The first interval's value of $W T$ and perhaps the $R S$ are distorted by this action too.

The findings in this section are consistent with other studies investigating patterns in intraday activity. ${ }^{18}$ The ASE trading activity exhibits intraday commonality. The study on the Swiss market by Ranaldo ${ }^{27}$, however, characterises the pattern of trading volume as having a triple U-shape. Ekinci ${ }^{28}$ observes a W-shape: an inverse J-curve at the morning session and a U-curve at the afternoon session in the Istanbul Stock Exchange.Learning from sequential trades, especially when the TS is large, causes spread to narrow and the time between subsequent trades to increase toward the middle time of the trading session, as suggested by Easly and O'Hara. ${ }^{19}$ As both timing and quantities of trades are directly observable to all market participants in the ASE, this study agrees with the explanation suggested by those studies in explaining the behaviour of trading activity at the open and the middle of the trading session. The increase in spread and the overall trading activity just before the market close cannot, however, be explained by the high inventory holding costs as in Garman, ${ }^{10}$ Stoll, ${ }^{11}$, Amihud and Mendelson ${ }^{12,}$ and Ho and Stoll ${ }^{13}$ because no market-makers exist in the ASE. The higher number of large and instant trades toward the market close, along with the higher trading costs can be explained by increased institutional and large traders' activities at the close, which is an indication of speculative behaviour by those investors.

The same measurement procedures are repeated to investigate the consistency of the observed patterns explained above in the case of an active individual stock. Based on the 24 intervals' estimates for each stock presented in Table 1, stocks are ranked starting with the most liquid. The ranking of stocks based on each liquidity measure independently points out the position of the mean value of each measure. It can be inferred from our ranking that the stock UAIC (United Arab Investors Co.) is the most liquid stock among the 37 stocks according to 4 out of 8 liquidity measures (ie NT, TO, IT, and $L R$ ), and the second most liquid according to 3 other measures (ie TS, BT, and $W T$ ). The transaction data of this stock are, therefore, selected accordingly for the further investigation of liquidity patterns on an individual stock level and the remaining empirical work of the present study.

From our analysis of UAIC, we found the same patterns observed in the composed crossmarket index hold for all liquidity proxies of UAIC (figures are not shown here to preserve space). The highest observed activity level for UAIC is at the market open and toward the market close, whereas the lowest liquidity level is observed between 11.25 and 11.40am.

\section{Intraday market concentration}

Market liquidity does not depend only on volume and depth measures, but also on the distribution of volume expected to arrive in the future. ${ }^{27}$ The 'Gini index' represents a general proxy of size volume concentration for each period of $10 \mathrm{~min}$ for a sample period of two months' trading data of a highly active stock in 
order to estimate the extent to which a trading period is characterised by a small number of large trades or by trades with a homogenous size.

$$
\text { Gini }=\left[1-\sum_{t=1}^{n}\left(X_{t}-X_{t-1}\right)\left(Y_{t}-Y_{t-1}\right)\right]
$$

where $X_{h}$ is the cumulated number of ordered trade variables, for $h=0, \ldots, n$, with $X_{0}=0$, $X_{n}=1, Y_{h}$ is the cumulated $T S$, for $h=0, \ldots, n$, with $Y_{0}=0, Y_{n}=1$.

The individual stock of UAIC, which is classified as the most liquid stock among the sample of 37 stocks, is used for the empirical analysis of the Gini index. The intraday periods used for the analysis are the five-minute intervals previously described with the same data filtering procedures and for the same period (1st January, 2005-31st August, 2005).

The first step in estimating equation (9) is to order the trades $(i=1,2, \ldots, n)$ in interval $(t=1,2, \ldots, 24)$ for day $j(j=1,2, \ldots, J)$ in ascending order according to their size. Total NT in a five-minute interval is

$$
n=\sum_{t=1}^{n} t_{t, i}
$$

and the trade ratio $\left(X_{t, i}\right)$ is

$$
X_{t, i}=\frac{\sum_{t} t_{t, i}}{\sum_{t=1}^{n} t_{t, i}}
$$

The cumulated TS at the end of interval $t$ is

$$
\sum_{t=1}^{n} T S_{t, i}
$$

The ratio of cumulated $T S\left(Y_{t, i}\right)$ at the end of interval $t$ is

$$
Y_{t, i}=\frac{\sum_{t} T S_{t, i}}{\sum_{t=1}^{n} T S_{t, i}}
$$

Table 4 lists the measured Gini coefficients along with the total NT for the 24 five-minute
Table 4: Estimation of intraday market concentration

\begin{tabular}{rrll}
\hline & Intraday period & Gini coefficient & \# of trades \\
\hline 1 & $10.00-10.05$ & 0.670 & 2,349 \\
2 & $10.05-10.10$ & 0.655 & 2,866 \\
3 & $10.10-10.15$ & 0.669 & 2,652 \\
4 & $10.15-10.20$ & 0.645 & 2,677 \\
5 & $10.20-10.25$ & 0.708 & 2,512 \\
6 & $10.25-10.30$ & 0.671 & 2,375 \\
7 & $10.30-10.35$ & 0.656 & 2,203 \\
8 & $10.35-10.40$ & 0.655 & 2,101 \\
9 & $10.40-10.45$ & 0.657 & 1,929 \\
10 & $10.45-10.50$ & 0.676 & 2,000 \\
11 & $10.50-10.55$ & 0.664 & 2,154 \\
12 & $10.55-11.00$ & 0.680 & 1,952 \\
13 & $11.00-11.05$ & 0.675 & 2,012 \\
14 & $11.05-11.10$ & 0.690 & 1,897 \\
15 & $11.10-11.15$ & 0.671 & 1,897 \\
16 & $11.15-11.20$ & 0.667 & 1,754 \\
17 & $11.20-11.25$ & 0.643 & 1,786 \\
18 & $11.25-11.30$ & 0.650 & 1,744 \\
19 & $11.30-11.35$ & 0.665 & 1,715 \\
20 & $11.35-11.40$ & 0.630 & 1,743 \\
21 & $11.40-11.45$ & 0.667 & 1,976 \\
22 & $11.45-11.50$ & 0.680 & 1,951 \\
23 & $11.50-11.55$ & 0.669 & 2,254 \\
24 & $11.55-12.00$ & 0.646 & 3,029 \\
& & & \\
& Mean & 0.665 & 2,147 \\
\hline & & &
\end{tabular}

intervals constituting the trading day of the UAIC stock for the period 1st January, 2005 to 31st August, 2005.

The mean value for the Gini coefficient is 0.665 , with 14 observations above the mean, whereas the mean value of total $N T$ is 2,147 , with 10 observations above the mean. Figure 6 


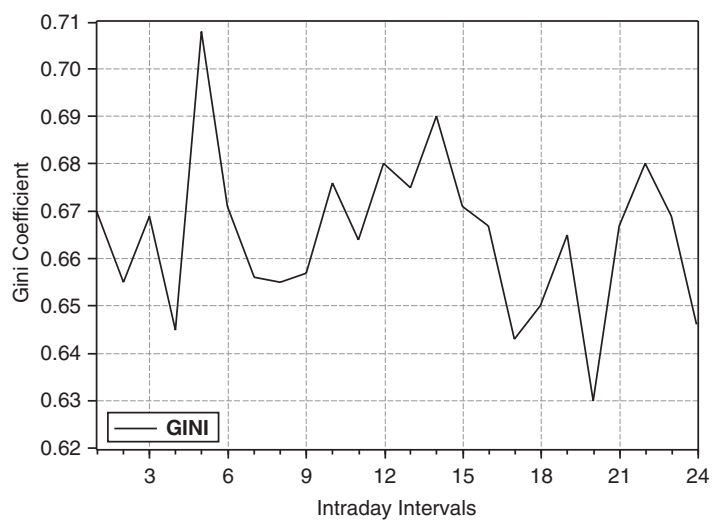

Figure 6: Gini coefficient

plots the estimated Gini coefficient values of the 24 intervals. No particular pattern can be identified from Figure 6.

The Gini coefficient reaches its maximum value (0.708) between 10.20 and 10.25. This is the period (labelled as fifth interval) that records a substantial increase in TS and TO - what can be described as a distortion in the U-shape. This increase is not accompanied by an increase in NT nor by the number of large trades. The heterogeneous TS at this interval cannot be clearly characterised or interpreted as a common behaviour. Actually, the high Gini coefficient at this period is a result of some outlier observations, such as one or more large trades of a significantly large size that increased the inequality of the distribution. The increase in the value of the liquidity ratio in the same interval confirms this explanation because it reflects a price impact of one or more potential large trade.

The lowest level of trade concentration is observed between 10.35 and 10.40 (labelled as the 20th interval). As shown earlier, the lowest activity level observed is between 11.25 and 11.40. This suggests that trades are more homogeneous when trading activity is lower. An advantage of the estimated Gini coefficient is that it measures the extent to which trades are homogeneous in size. Therefore, it is not biased toward large or small trades.

\section{SUMMARY AND CONCLUSIONS}

The study investigates the cross-market intraday behaviour of liquidity in the ASE using highfrequency data that is tick-by-tick transaction data for the period 1st January, 2005 to 31st August, 2005. We established eight different proxies representing the different liquidity dimensions for an index composed of 37 stocks averages. All of the used liquidity proxies appear to exhibit an identifiable pattern: volume measures (TS, TO, and NT), bid-ask spread, number of $I T$, and number of $B T$ exhibit the popular U-shape. Liquidity ratio exhibits a smooth L-shape, whereas time between subsequent trades can be better described as an inverse U-shape. According to the observed results, the highest liquidity levels at ASE are at the market open and market close, and the lowest active period is between 11.20 and $11.35 \mathrm{am}$. The results suggest the probability of high information asymmetry at the opening of trade day and a probable extensive institutional and large investor's activity toward the market close.

The results observed for the composed market index are also observed for the case of an individual active stock, for which a further investigation is held to analyse intraday trade concentration. This is achieved by estimating the Gini coefficient in order to examine the extent to which trading volume is characterised by small homogenous trades or a small number of larger trades. No particular pattern is observed. 


\section{References and Notes}

1 Kyle, A. (1985) 'Continuous Auctions and Insider Trading', Econometrica, Vol. 53, pp. 1315-1335.

2 Harris, L.E. (1990) 'Liquidity, Trading Rules, and Electronic Trading Systems', Monograph Series in Finance and Economics No. 1990-4, Salomon Center, New York University.

3 Madhavan, A. (2000) 'Market Microstructure: A Survey', Journal of Financial Markets, Vol. 3(August), pp. 205-258.

4 Madhavan, A. (2002) 'Market Microstructure: A Practitioner's Guide', Financial Analysis Journal, Vol. 58, No. 5, pp. 28-42.

5 Stoll, H. (2003) 'Market Microstructure', Financial Markets Research Center, Working Paper, No. 01-16.

6 Freyre-Sanders, A., Guobuzaite, R. and Byrne, K. (2004) 'A Review of Trading Cost Models: Reducing Transaction Costs', The Journal of Investing, Vol. 13, pp. 93-115.

7 O'Hara, M. (2003) 'Presidential Address: Liquidity and Price Discovery', Journal of Finance, Vol. 58, pp. 1335-1354.

8 Demsetz, H. (1968) 'The Cost of Transacting', Quarterly Journal of Economics, Vol. 82, pp. 33-53.

9 Tinic, S. (1972) 'The Economics of Liquidity Services', Quarterly Journal of Economics, Vol. 66, pp. 79-97.

10 Garman, M. (1976) 'Market Microstructure', Journal of Financial Economics, Vol. 3, pp. 257-275.

11 Stoll, H. (1978) 'The Supply of Dealer Services in Securities Markets', Journal of Finance, Vol. 33, pp. 1133-1151.

12 Amihud, Y. and Mendelson, H. (1980) 'Dealership Market: Market Making with Inventory', Journal of Financial Economics, Vol. 8, pp. 31-53.

13 Ho, T. and Stoll, H. (1981) 'Optimal Dealer Pricing under Transaction and Return Uncertainty', Journal of Financial Economics, Vol. 9, pp. 47-73.

14 Copeland, T. and Galai, D. (1983) 'Information Effects and the Bid-Ask Spread', Journal of Finance, Vol. 38, pp. 1457-1469.

15 Glosten, L.R. and Milgrom, P. (1985) 'Bid, Ask, and Transaction Prices in a Specialist Market with Heterogeneously Informed Agents', Journal of Financial Economics, Vol. 14, pp. 71-100.

16 Glosten, L.R. (1987) 'Components of the Bid-Ask Spread and the Statistical Properties of Transaction Prices', Journal of Finance, Vol. 42, pp. 1293-1307.
17 Easley, D. and O'Hara, M. (1992) 'Time and the Process of Security Price Adjustment', Journal of Finance, Vol. 47, pp. 577-606

18 Admati, A.R. and Pffeiderer, P. (1988) 'A Theory of Intraday Trading Patterns', Review of Financial Studies, Vol. 1, pp. 3-40.

19 Easley, D. and O’Hara, M. (1987) 'Price, Trade Size, and Information in Securities Markets', Journal of Financial Economics, Vol. 19, pp. 69-90.

20 Hasbrouck, J. (1991) 'Measuring the Information Content of Stock Trades', Journal of Finance, Vol. 46, pp. 178-208.

21 Subrahmanyam, A. (1991) 'A Theory of Trading in Stock Index Futures', Review of Financial Studies, Vol. 4, pp. 17-51.

22 Stoll, H. (1989) 'Inferring the Components of the Bid-Ask Spread: Theory and Empirical Tests', Journal of Finance, Vol. 44, pp. 115-134.

23 Lin, J., Sanger, G. and Booth, G. (1995) 'Trade Size and the Components of the Bid-Ask Spread', Review of Financial Studies, Vol. 8, No. 4, pp. 1153-1183.

24 Cushing, D. and Madhavan, A. (2001) 'The Hidden Cost of Trading at the Close', in Burce, B. (ed.) 'Transaction Costs: A Cutting Edge Guider to Best Execution', Institutional Investor, New York, pp. 12-19.

25 Ghysels, E. and Cherkaoui, M. (1999) 'Emerging Markets and Trading Costs', Centre Interuniversitaire de Recherche en Analyse des Organisations CIRANO Working Papers 99s-904.

26 ASE Official Website: www.ammanstockex.com.

27 Ranaldo, A. (2000) 'Intraday Trading Activity on Financial Markets: The Swiss Evidence', $\mathrm{PhD}$ thesis, University of Fribourg.

28 Ekinci, C. (2004) 'A Statistical Analysis of Intraday Liquidity, Returns and Volatility of an Individual Stock from the Istanbul Stock Exchange. http://econpapers. repec.org/RAS/pek1.htm.

29 Roll, R. (1984) 'A Simple Implicit Measure of the Bid-Ask Spread in an Efficient Market', Journal of Finance', Vol. 39, pp. 1127-1139.

30 Chordia, T., Roll, R. and Subrahmanyam, A. (2000) 'Commonality in Liquidity', Journal of Financial Econometrics, Vol. 56, pp. 3-28. 


\begin{tabular}{|c|c|c|c|c|c|c|c|c|c|c|c|}
\hline \multicolumn{12}{|c|}{$\begin{array}{l}\text { APPENDIX A } \\
\text { See Table A1. }\end{array}$} \\
\hline No. & Company's name & Reuters code & Code & Sector & $\begin{array}{l}\text { Listing } \\
\text { market }\end{array}$ & $\begin{array}{l}\# \text { of } \\
\text { trading } \\
\text { days }\end{array}$ & $\begin{array}{l}\text { Average } \\
\text { trades per } \\
\text { days }\end{array}$ & $\begin{array}{l}\text { Average } \\
\text { turnover }\end{array}$ & $\begin{array}{l}\text { Average } \\
\# \text { shares }\end{array}$ & $\begin{array}{l}\text { \# of } \\
\text { trades before } \\
\text { filtering }\end{array}$ & $\begin{array}{l}\text { \# of trades } \\
\text { after } \\
\text { filtering }\end{array}$ \\
\hline 1 & $\begin{array}{l}\text { Jordan Islamic Bank For Finance } \\
\text { \& INV. }\end{array}$ & JOIB & 111001 & Banking & 1 & 164 & 308.884 & $4,868.763$ & $1,193.78$ & 50,657 & 30,110 \\
\hline 2 & Jordan Kuwait Bank & JOKB & 111002 & Banking & 1 & 164 & 50.957 & $5,581.991$ & 478.586 & 8,353 & 6,209 \\
\hline 3 & Jordan Commercial Bank & JOGB & 111003 & Banking & 1 & 165 & 83.576 & $4,763.652$ & 822.961 & 13,792 & 12,843 \\
\hline 4 & $\begin{array}{l}\text { The Housing Bank for Trade } \\
\text { and Finance }\end{array}$ & THBK & 111004 & Banking & 1 & 164 & 56.226 & $11,037.614$ & 883.551 & 9,921 & 6,465 \\
\hline 5 & Industrial Development Bank & INDV & 111006 & Banking & 1 & 165 & 249.200 & $5,410.491$ & $1,391.155$ & 41,118 & 24,477 \\
\hline 6 & Union Bank for Saving \& Investment & UBSI & 111007 & Banking & 1 & 164 & 62.787 & $11,890.885$ & $1,275.277$ & 10,297 & 7,094 \\
\hline 7 & Jordan Investment \& Finance Bank & JIFB & 111014 & Banking & 1 & 164 & 105.378 & $7,097.907$ & $1,373.754$ & 17,284 & 11,702 \\
\hline 8 & Capital Bank of Jordan & EXFB & 111017 & Banking & 1 & 161 & 126.472 & $6,979.073$ & $1,166.876$ & 20,362 & 13,423 \\
\hline 9 & Cairo Amman Bank & CABK & 111021 & Banking & 1 & 164 & 106.341 & $10,972.990$ & 968.409 & 17,440 & 11,556 \\
\hline 10 & Bank of Jordan & BOJX & 111022 & Banking & 1 & 164 & 137.604 & $7,459.070$ & 996.293 & 22,567 & 14,892 \\
\hline 11 & $\begin{array}{l}\text { Beit Al-Mal Saving \& Investment for } \\
\text { Housing }\end{array}$ & BAMB & 111027 & Service & 1 & 164 & 185.543 & $2,793.072$ & 579.009 & 30,429 & 18,374 \\
\hline 12 & Jordan Electric Power & JOEP & 131004 & Service & 1 & 165 & 117.188 & $4,059.388$ & 773.299 & 19,336 & 13,095 \\
\hline 13 & Real Estate Investment/Aqarco & REIN & 131017 & Service & 1 & 164 & 99.585 & $1,437.219$ & $1,084.391$ & 16,332 & 9,095 \\
\hline 14 & $\begin{array}{l}\text { Jordanian Expatriates Investment } \\
\text { Holding }\end{array}$ & JEIH & 131025 & Service & 1 & 164 & 108.360 & $4,176.762$ & 733.767 & 17,770 & 11,078 \\
\hline 15 & Union Investment Corporation & UINV & 131069 & Service & 1 & 163 & 529.497 & $9,610.101$ & $1,114.986$ & 116,714 & 49,542 \\
\hline 16 & $\begin{array}{l}\text { Union Land Development } \\
\text { Corporation }\end{array}$ & ULDC & 131073 & Service & 1 & 161 & 239.696 & $7,180.363$ & $1,521.147$ & 54,551 & 22,556 \\
\hline
\end{tabular}




\begin{tabular}{|c|c|c|c|c|c|c|c|c|c|c|c|}
\hline \multicolumn{12}{|c|}{ Table A1: Continued } \\
\hline No. & Company's name & Reuters code & Code & Sector & $\begin{array}{l}\text { Listing } \\
\text { market }\end{array}$ & $\begin{array}{l}\text { \# of } \\
\text { trading } \\
\text { days }\end{array}$ & $\begin{array}{l}\text { Average } \\
\text { trades per } \\
\text { days }\end{array}$ & $\begin{array}{l}\text { Average } \\
\text { turnover }\end{array}$ & $\begin{array}{l}\text { Average } \\
\text { \# shares }\end{array}$ & $\begin{array}{l}\text { \# of } \\
\text { trades before } \\
\text { filtering }\end{array}$ & $\begin{array}{l}\text { \# of trades } \\
\text { after } \\
\text { filtering }\end{array}$ \\
\hline 17 & $\begin{array}{l}\text { Al-Tajamouat for Catering and } \\
\text { Housing Co Plc }\end{array}$ & JNTH & 131076 & Service & 1 & 164 & 82.622 & $1,427.845$ & $1,144.692$ & 13,550 & 7,648 \\
\hline 18 & Specialized Investment Compounds & SPIC & 131077 & Service & 1 & 164 & 142.970 & 3,227.992 & 865.199 & 23,447 & 14,933 \\
\hline 19 & United Arab Investors & UAIC & 131079 & Service & 1 & 164 & 541.201 & $9,961.825$ & 987.841 & 88,757 & 51,868 \\
\hline 20 & Jordan Express Tourist Transport & JETT & 131080 & Service & 1 & 165 & 88.339 & $3,663.181$ & $1,061.737$ & 14,576 & 10,000 \\
\hline 21 & Arab East Investment & AEIV & 131082 & Service & 1 & 159 & 175.981 & $9,372.478$ & $1,130.651$ & 27,981 & 17,160 \\
\hline 22 & Real Estate Development & REDV & 131087 & Service & 1 & 157 & 176.739 & $3,277.408$ & $1,334.165$ & 26,059 & 14,334 \\
\hline 23 & Al-Amin for Investment & AAFI & 131089 & Service & 1 & 162 & 76.586 & $4,768.743$ & $1,003.590$ & 12,407 & 8,315 \\
\hline 24 & Jordan Telecom & JTEL & 131206 & Service & 1 & 164 & 248.457 & $4,597.250$ & 844.303 & 69,427 & 25,319 \\
\hline 25 & Jordan Petroleum Refinery & JOPT & 142041 & Industrial & 1 & 164 & 139.280 & $4,340.165$ & 650.357 & 22,842 & 15,378 \\
\hline 26 & Jordan Phosphate Mines & JOPH & 141018 & Industrial & 1 & 164 & 79.646 & $3,835.486$ & 812.640 & 2,862 & 1,967 \\
\hline 27 & National Cable \& Wire Manufacturing & WIRE & 141039 & Industrial & 1 & 163 & 94.988 & $3,135.296$ & 920.830 & 15,482 & 10,068 \\
\hline 28 & International Tobacco \& Cigarettes & ITCC & 141048 & Industrial & 1 & 163 & 120.393 & $5,369.483$ & $1,058.555$ & 19,624 & 12,496 \\
\hline 29 & National Chlorine Industries & NATC & 141054 & Industrial & 1 & 163 & 94.988 & $3,135.296$ & 920.830 & 11,729 & 7,471 \\
\hline 30 & El-Zay Ready Wear Manufacturing & ELZA & 141061 & Industrial & 1 & 163 & 88.583 & $1,702.970$ & $1,244.019$ & 14,439 & 8,577 \\
\hline 31 & International Ceramic Industries & ICER & 141078 & Industrial & 1 & 164 & 76.768 & $2,050.029$ & $1,565.844$ & 12,590 & 7,481 \\
\hline 32 & $\begin{array}{l}\text { Societe Generale De Banque - } \\
\text { Jordanie }\end{array}$ & MEIB & 111020 & Banking & 2 & 164 & 110 & $5,372.187$ & $2,040.878$ & 18,106 & 11,466 \\
\hline 33 & $\begin{array}{l}\text { Jordan Investment \& Tourism } \\
\text { Transport(ALFA) }\end{array}$ & ALFA & 131083 & Service & 2 & 165 & 219.485 & $2,069.970$ & $1,349.114$ & 36,216 & 19,152 \\
\hline 34 & Arab Real Estate Development & ARED & 131092 & Service & 2 & 163 & 98.7607362 & $1,881.835$ & $1,131.51$ & 16,098 & 9,366 \\
\hline 35 & $\begin{array}{l}\text { The Real Estate \& Investment } \\
\text { Portfolio Co. }\end{array}$ & PETT & 131101 & Service & 2 & 162 & 121.846 & $5,677.992$ & $1,993.749$ & 19,739 & 11,584 \\
\hline
\end{tabular}


Table A1: Continued

\begin{tabular}{|c|c|c|c|c|c|c|c|c|c|c|c|}
\hline No. & Company's name & Reuters code & Code & Sector & $\begin{array}{l}\text { Listing } \\
\text { market }\end{array}$ & $\begin{array}{l}\text { \# of } \\
\text { trading } \\
\text { days }\end{array}$ & $\begin{array}{l}\text { Average } \\
\text { trades per } \\
\text { days }\end{array}$ & $\begin{array}{l}\text { Average } \\
\text { turnover }\end{array}$ & $\begin{array}{l}\text { Average } \\
\# \text { shares }\end{array}$ & $\begin{array}{l}\# \text { of } \\
\text { trades before } \\
\text { filtering }\end{array}$ & $\begin{array}{l}\text { \# of trades } \\
\text { after } \\
\text { filtering }\end{array}$ \\
\hline 36 & $\begin{array}{l}\text { The Investors and Eastern Arab } \\
\text { for Industrial and Real Estate } \\
\text { Investments }\end{array}$ & IEAI & 131217 & Service & 2 & 164 & 279.030 & $5,944.833$ & $1,310.254$ & 45,764 & 26,906 \\
\hline 37 & $\begin{array}{l}\text { The Industrial Commercial } \\
\text { \& Agricultural }\end{array}$ & ICAG & 141009 & Industrial & 2 & 163 & 143.104 & $1,774.916$ & $1,238.805$ & 23,326 & 13,168 \\
\hline
\end{tabular}

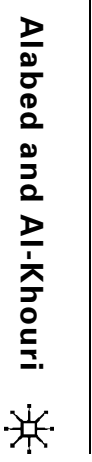

